\title{
O lugar da analítica existencial no projeto heideggeriano de uma ontologia fundamental
}

\author{
The place of existential analytical in the heideggerian project of a \\ fundamental ontology
}

\author{
KATYANA MARTINS WEYH ${ }^{1}$
}

\begin{abstract}
Resumo: O objetivo deste artigo é apresentar os termos do programa da ontologia fundamental heideggeriana evidenciando, inclusive, seus subprojetos, conjunto que visa a retomada da questão do ser por meio de seu sentido. O esforço por retomar tais temas se viabiliza por meio do recurso à obra Ser e tempo (1927), em que Heidegger mostra a necessidade de voltar à metafísica tradicional para compreender como esta interpreta a ontologia e de que modo lida com a questão ontológica. Dessa maneira, o presente artigo aborda, primeiramente, o que ficou conhecido como retomada da questão fundamental do sentido do ser, a diferença entre ser e ente e a caracterização do "fenômeno humano" (Ser-aí). Pretende-se, com isso, apresentar a ideia central da ontologia fundamental e mostrar em que medida ela difere da ontologia tradicional, para, a partir daí, apresentar os subprojetos de Ser e Tempo, pertencentes ao projeto da ontologia fundamental, a saber: destruição da história da ontologia, hermenêutica da facticidade e, por fim, a analítica existencial.
\end{abstract}

Palavras-chave: Heidegger. Ser-aí. Analítica existencial.

Abstract: The objective of this article is to present the terms of the Heideggerian fundamental ontology program, evidencing even its subprojects, a set that aims at the resumption of the question of being through its meaning. The effort to retake such themes is made possible through the use of Being and Time (1927), in which Heidegger shows the need to return to traditional metaphysics to understand how it interprets the ontology and how it deals with the ontological question. In this way, the present article addresses, firstly, what was known as a resumption of the fundamental question of the sense of being, the difference between being and entity and the characterization of the "human phenomenon" (Da-sein). It is intended, therefore, to present the central idea of the fundamental ontology, And show how it differs from the traditional ontology, to, from there, present the subprojects of Being and Time, belonging to the project of the fundamental ontology, are: destruction of the history of the ontology, hermeneutics of the facticity and, finally, the existential analytic.

Keywords: Heidegger. Da-sein. Existential analytical.

\section{A retomada da questão do ser pelo seu sentido}

Martin Heidegger (1889-1976) foi um filósofo alemão cujo pensamento radicalizou o filosofar contemporâneo; essa radicalidade reside no resgate da questão que - embora situada no cerne da filosofia - permanecia negligenciada em sua história. Tal questão que, segundo Heidegger, deixou de ser pensada e discutida,

\footnotetext{
${ }^{1}$ Graduada em Licenciatura em Filosofia pela Universidade Estadual do Oeste do Paraná (Toledo/PR), graduada em Psicologia pela Faculdade Anhanguera Educacional (Cascavel/PR), mestranda em Filosofia pela Universidade Estadual do Oeste do Paraná (Toledo/PR). Desenvolve pesquisas na área de psicologia e fenomenologia, com ênfase no autor alemão Martin Heidegger. E-mail: katian.na@hotmail.com
} 
inclusive pelos mais clássicos pensadores, tornou-se protagonista na filosofia de nosso autor. A retomada da questão do ser pela abordagem de seu sentido é, portanto, o fio condutor do projeto de uma fenomenologia ontológico-existencial.

A fim de compreender como essa temática do ser chegou a constituir uma questão para Heidegger, precisamos compreender que um dos principais motivos que levaram o filósofo a se interessar pelo assunto foi "[...] a leitura da obra de Franz Brentano, Von der mannigfachen Bedeutung des Seienden nach Aristoteles ${ }^{2}$ (1862), presenteada ao jovem colegial, no verão de 1907, por seu conterrâneo e amigo paternal, Dr. Konrad Gröber" (MACDOWELL, 1993, p. 23-34). O filósofo afirma que este foi o principal impulso para pensar a questão que perpassaria toda a sua filosofia:

Da múltipla significação do ente em Aristóteles (1862), tinha sido justamente, desde 1907, o guia e o critério das minhas primeiras e desajeitadas tentativas de penetrar na filosofia. De uma forma bastante imprecisa, o que me movia era a seguinte reflexão: "se o ente se diz com significados múltiplos, qual será então o significado fundamental e condutor? O que significa ser?" (HEIDEGGER, 2009a, p. 3-4).

Impulsionado por estas questões, Heidegger percebeu como a tradição sempre se reportou ao ser como um ente simplesmente dado. A pergunta pela significação do ser soava trivial a ponto de ser deixada de lado, sem que se questionasse o que entendemos pela expressão "ser". Desse modo, segundo nosso pensador, a metafísica ocupou-se de pensar apenas o ente e sua constituição ontológica (HEIDEGGER, 2012a).

Enquanto a pergunta metafísica diz respeito à essência natural do ente, caracterizada como substância, categoria, quididade, etc., o ser dos entes passou a ser definido, também, desde essa visada, razão pela qual a metafísica tradicional se manteve em um domínio meramente ôntico. No entanto, Heidegger compreende e afirma, em Ser e tempo, que o ser não pode ser definido, pois é o conceito "mais universal", "indefinível" e "evidente por si mesmo". Devido a isso, é considerada equívoca a tentativa de dizer o ser a partir de definições, pois:

[...] é justamente nas alegações de que o ser é o conceito mais universal, indefinível e evidente por si mesmo, usadas para desqualificar qualquer retomada do tema, que Heidegger encontrará indícios de que a ontologia tradicional deixou impensado o que havia de mais fundamental no ser [...]. Isso porque, toda vez que a filosofia (= tradição metafísica) foi ao ser, já sempre o interpretou equivocamente como também um ente (= uma coisa que é), um ente supremo, supostamente mais fundamental (um "super-ente" se assim desejássemos), mas que, ainda assim, traria determinações ônticas (KAHLMEYER-MERTENS, 2015, p. 42-43).

\footnotetext{
${ }^{2}$ Em português: Das múltiplas significações do ente segundo Aristóteles.
} 
Isso prova que o ser consolidou-se como um conceito soterrado sob premissas teóricas e interpretações derivadas, distorcendo-se ou, mesmo, encobrindo-se por completo o seu sentido. A partir de tal descoberta, que justifica nossa indicação acima sobre a "radicalidade" do pensamento de Heidegger, o fato de perceber que o ser não pode ser definido nos leva a compreender que este também não pode ser determinado, a menos que o seja feito pelo seu sentido mais próprio. Para que isso seja possível, Heidegger apresenta, logo no primeiro capítulo (§.1) de Ser e tempo: "[...] a necessidade de uma repetição explícita da questão do ser" e afirma que "[...] não somente falta resposta à questão do ser mas que a própria questão é obscura e sem direção. Repetir a questão do ser significa, pois, elaborar primeiro, de maneira suficiente, a colocação da questão". (HEIDEGGER, 2008b, p. 30).

Mas de que modo, então, Heidegger coloca a questão? Efetivamente, reformulando a pergunta de modo a ela não soar metafísica. Não mais se tem interesse em saber sobre o "conceito de ser", ou seja, o que é o ser, uma vez que compreendemos que sua definição não é possível, a menos que se dê por meio de seu sentido. Em vista disso, Heidegger rompe com o pensamento tradicional, e passa a investigar qual o sentido do ser dos entes.

Na recolocação da pergunta, visando o sentido do ser, Heidegger parte da ideia de que todo questionamento é uma procura. Isso se dá porque a questão do ser passa a ser uma procura pelo seu sentido de possibilidades, afastando-se, assim, por completo de definições ou determinações. Para que a questão do sentido do ser possa ser recolocada, Heidegger apresenta a tríplice estrutura formal da questão: perguntado, interrogado e questionado:

Toda questão se desdobra, formalmente, em três pólos: de um lado, há aquilo que questionamos, o questionado (das Gefragte), o que perguntamos a seu respeito, o perguntado (das Erfragte), e aquilo que interrogamos para obter, a respeito do questionado, o perguntado: o interrogado (das Befragte) (DUBOIS, 2004, p. 15).

Feita esta apresentação sumária, que pretendeu introduzir elementos para tornar compreensível a questão do sentido do ser em Heidegger, tratamos do que é questionado (o próprio ser) e do que, nessa pergunta fundamental, deve ser interrogado. Esse interrogado, no entanto, conta sempre com uma pré-compreensão de ser. A este interrogado, que é o único capaz de compreender ser e questionar seu sentido, Heidegger denomina ser-aí (Dasein). Uma caracterização dessa figura é o que se segue.

\section{Ser-aí e a diferença ontológica}

A partir da apresentação da questão do sentido do ser, Heidegger expõe uma 
importante diferenciação, a qual chama de "diferença ontológica"3. Essa noção, de início, aponta para uma distinção entre ser e ente, para explicitar que aquilo que conhecemos como ente é do domínio ôntico (são as coisas, animais, objetos, utensílios, etc.) enquanto que aquilo que podemos compreender é relacionado ao sentido do ser, sendo compreendido em um âmbito ontológico.

Este ente Heidegger denominou como o interrogado, a quem a pergunta fundamental sobre o sentido do ser pode ser feita. Este ente não é compreendido como um simplesmente dado, como os entes do domínio ôntico, mas como um ente ôntico-ontológico, que difere dos demais por já sempre partir de uma compreensão prévia de ser. A esse ente específico e privilegiado Heidegger chama ser-aí (Dasein). A diferença ontológica, portanto, se revela no próprio ser-aí, uma vez que ele mesmo se mostra nessa diferença, por ser o "espaço" de significado desde o qual algo como ser e ente podem aparecer como distintos.

Para o ser-aí, a "possibilidade de questionamento nasce da própria questão - da pergunta do sentido do ser, que se deve fazer, e que tacitamente o Dasein já faz" (NUNES, 2012, p.74), pois o ser-aí é um ente que lida com o seu próprio ser, com a sua própria existência. Podemos compreender que o "ser-aí" diz respeito ao modo de ser do "fenômeno humano", ente que nós mesmos somos, que compreende ser e questiona seu sentido. Segundo Heidegger:

Esse ente que cada um de nós somos e que entre outras, possui em seu ser a responsabilidade de questionar, nós o designamos com o termo ser-aít . A colocação explícita e transparente da questão sobre o sentido do ser requer uma explicitação prévia e adequada de um ente (ser-aí) no tocante a seu ser" (HEIDEGGER, 2008b, p.33).

A passagem acima citada é o momento em que, pela primeira vez, o termo ser-aí aparece em Ser e tempo. Ao se referir ao ser-aí, Heidegger o apresenta como modo de ser de um ente; mas não um ente qualquer, trata-se do ente que nós (fenômeno humano) somos. Esse ente tem um caráter específico e sua peculiaridade diz respeito a ele ser responsável por compreender sua própria existência e, além disso, interrogála. Somente ao ser-aí é possível esta tarefa, uma vez que nenhum outro ente compreende e se revela como diferença ontológica.

No entanto, o ser-aí, como modo de ser do ente que nós mesmos somos, é um

\footnotetext{
3 Em Ser e tempo, o termo "diferença ontológica" não é explicitamente usado por Heidegger; no entanto, nessa obra, tal diferença se faz sentir nos contextos fenomenológicos do projeto heideggeriano. Uma notícia histórica sobre a presença da diferença ontológica nos primeiros momentos da filosofia de Heidegger é o que se encontra na narrativa de Gadamer (2012), especialmente na página 70.

${ }^{4}$ Optamos por utilizar a tradução de Ser e tempo feita por Márcia Sá Cavalcante Schuback (2002). No entanto, em nosso texto substituímos deliberadamente as traduções de "pre-sença" por ser-aí. A fim de não nos distanciarmos dos mais precisos conceitos utilizados por Heidegger, utilizamos, como suporte, a tradução de Ser e tempo organizada por Fausto Castilho (2012b), disponível em edição bilíngue.
} 
ente diferenciado, pois tem o caráter privilegiado da existência e a existência, nesse caso, difere de um mero estar-aí no mundo (condição das coisas/entes simplesmente dados). O caráter de existência (ser-aí), nesse caso, só é possível àquele que a compreende enquanto condição de possibilidades e ausência de determinação, enquanto que o caráter de estar-aí é específico dos demais entes, aqueles que não possuem o traço fundamental do existir.

É isto que Dubois (2004) tem em vista quando responde à seguinte questão: Qual o modo de ser específico do ser-aí? "A existência [...] A palavra Existenz não significa existentia enquanto realidade. A princípio, trata-se claramente de um vocábulo ontológico, a existência é o modo de ser do ser-aí. E apenas dele. Só o ser-aí existe. O rochedo, ou a colher, ou Deus não existem" (p. 17). Assim percebemos que não devemos interpretar o ser-aí na chave do mero ente, como o fez a tradição metafísica; o que dele poderíamos afirmar, à guisa de uma caracterização positiva, seria que ele é um poder-ser que se realiza por meio da existência no mundo.

Desse modo, Heidegger afirma que a "essência" desse ente está em sua existência, evidenciando que as características que se podem dele "extrair" não são categorias. "O 'ser-aí' é uma palavra para designar o nosso poder ser" (FIGAL, 2016, p.6o). Isso mostra que o ser-aí em si mesmo é designado como puro poder-ser e se determina como ente sempre a partir das possibilidades que assume, e esse é o sentido de sua constituição ontológico-existencial.

Devido a isso, a questão do ser-aí como um ser de possibilidades se explica como um ser lançado para fora, ser aberto para as possibilidades do seu mundo. No entanto, a ideia de lançar-se para fora não tem sentido espacial geográfico, mas o de ex-sistência. O prefixo ex, neste caso, indica um horizonte aberto em que as coisas aparecem e têm sentido. Essa exposição encontra fundamentação na seguinte passagem de Oswaldo Giacóia Jr (2013, p. 63):

[...] o Dasein é o ente a cuja essência pertence o ser; que existe (é) enquanto aí - no aberto, em abertura para o Ser. Essa é a condição ontológica do homem como Dasein, como ser-o-aí. Nesse sintagma, " $d a$ " não deve ser tomado em acepção espacial, como se indicasse uma localização, um "aqui" contraposto a "lá" ou "acolá". Em Ser e tempo, o "aí" significa uma dimensão de exterioridade, como a expressa pelo prefixo latino ex - em "expelir" ou "extirpar".

Entendemos que foi com o objetivo de evitar equívocos, tais como o de compreender o termo ser-aí como uma espécie de continente-conteúdo (em que um se encontra dentro do outro), que Heidegger sugere que o termo ser-aí seja traduzido para o francês por “"être le là" (ser o aí), e não "être là" (ser aí)” (DASTUR; CABESTAN, 2015, p. 53) ${ }^{5}$. Desse modo, a chance de compreender o aí do ser com uma conotação

\footnotetext{
5 Esta indicação também aparece nos Seminários de Zollikon: "A tradução francesa apropriada para Dasein deveria ser: être lê là (HEIDEGGER, 200gb, p. 159).
} 
espaço-física seria menor.

Portanto, falar do ser-aí, como experiência paradigmática do humano, significa dizer que esse é um ente cuja essência consiste em "ex-sistir". Uma citação de Heidegger em Seminários de Zollikon deixa evidente o conceito e significado de ser-aí: "A palavra ser-aí (Dasein) significa comumente estar presente, existência. [...] Em Ser e tempo, o -aí $[\mathrm{Da}]$ não significa uma definição de lugar para um ente, mas indica a abertura na qual o ente pode estar presente para o homem, inclusive ele mesmo para si." (HEIDEGGER, 2009b, p. 159).

Sendo assim, o ser-aí já sempre se mostra como um poder ser, ou seja, sua existência está sempre na dimensão de um horizonte aberto, em que a existência enquanto possibilidade é a sua única determinação possível. Para que seja melhor compreendida a existência do ser-aí, sua caracterização e especificidade, Heidegger desenvolveu seu pensamento ontológico baseado em um projeto que resguarda ao ser-aí um espaço privilegiado. Este projeto passa, então, a ser caracterizado mais minuciosamente no tópico que segue.

\section{O projeto da Ontologia fundamental}

Ao circunscrever a base de seu pensamento, Heidegger apresenta uma ideia que tem por finalidade designar a totalidade do seu projeto filosófico. Essa ideia, que tem por objetivo reabilitar a investigação ontológica por meio da questão do sentido do ser é denominada, em Ser e tempo, ontologia fundamental.

Ao perceber que a ontologia tradicional cometeu o equívoco de interpretar o ser (determinação ontológico-fundamental) como um ente entre os outros, de modo que o ser do ser-aí fora sempre compreendido como um ente simplesmente dado, Heidegger ocupou-se de uma desconstrução da história da ontologia. Nessa desconstrução, o filósofo pretendia oferecer novos rumos à metafísica contemporânea, principalmente por propor uma ontologia fundamental que partisse da questão primeira (novamente: a questão do sentido do ser), que sustenta todas as demais ontologias.

Heidegger investiu em uma ontologia fundamental, que leva em consideração a diferença ontológica, rompendo com os moldes tradicionais e deterministas da ontologia clássica. Para instaurar esse novo modo ontológico de pensar, Heidegger propõe, como um dos subprojetos de sua ontologia fundamental, a desconstrução, ou mesmo, a "destruição" da história da ontologia. Essa destruição, no entanto, não tem um objetivo negativo, nem mesmo a intenção de abandonar todo o legado histórico herdado da tradição metafísica, mas, muito mais do que isso, desconstruir

[...] significa, de fato, reconstruir, visto que se trata de reencontrar um solo de origem, uma base fenomenal com conceitos usados, dado que se trata "ao des-construir representações tornadas usuais e 
vazias... de recuperar as experiências do ser que estão na origem da metafísica". O essencial da des-construção - sem a qual ela se reduziria a tornar a atravessar as sedimentações dos sentidos consiste na reconquista duma experiência originária e simples do ser, quer dizer, numa descoberta fenomenológica, pela qual é possível ver de novo uma estrutura elementar esquecida (HAAR, 1990, p. 120-121).

A fim de compreender melhor tal explicação, devemos refletir sobre este momento em que o pensar metafísico tradicional é desconstruído. Desconstruir esse legado não significa esquecimento, restrição ou ruína, pois tal pensamento, mesmo que insuficiente para uma ontologia fundamental, serve de base para tais discussões, uma vez que reinsere e coloca novamente em discussão a questão mais primordial da metafísica que havia sido esquecida.

A partir disso, devemos repensar e recolocar a questão do sentido do ser, em que o ser-aí possa compreender e questionar sua própria existência enquanto diferença frente aos demais entes. Devido a isso, o projeto da ontologia fundamental não recusa a filosofia e sua história, nem se distancia abruptamente, mas trata de continuar nesse caminho filosófico, de modo a ocupar-se das questões anteriormente deixadas de lado.

É indispensável, no entanto, que se reconsidere o modo de fazer ontologia, pois a metafísica sempre compreendeu o ser-aí a partir da dicotomia sujeito-objeto, classificando o ser do ente que nós somos de maneira reificada, ou seja, como coisa (res) dotada de substância ou qualquer outro pressuposto essencial, quididativo. Heidegger afirma que essas representações perdem de vista o traço essencial do ser-aí como condição de possibilidades e "a questão do sentido do ser reclama portanto desde si mesma que sua situação histórica seja esclarecida, que o Dasein questionante se aposse da situação de sua interpretação" (DUBOIS, 2004, p. 21).

O ser-aí é responsável por resgatar a questão que a ontologia tradicional deixou cair no esquecimento, fazendo com que a desconstrução da história da metafísica, constitua também uma "superação" ou "transpassamento" (FIGAL, 2005) do equívoco cometido pela tradição. Esse transpassamento ou superação marca um novo modo de pensar e fazer ontologia, que diz respeito à redescoberta da questão mais primordial e que dá fundamento a todo questionamento ontológico. Redescobrir e reinserir a questão do sentido do ser, portanto, faz com que a ontologia assuma um novo caráter frente a sua história, um caráter fundamental, no sentido de que funda e respalda toda e qualquer discussão que se pretenda ontológico-existencial.

Não é apenas, porém, a desconstrução da história da ontologia que faz parte do projeto da ontologia fundamental; há também dois outros subprojetos de grande importância: a hermenêutica da facticidade e a analítica existencial. A hermenêutica da facticidade, embora não seja tratada com tanta profundidade em Ser e tempo, é apresentada desde o "movimento" da tríplice estruturação da questão do ser 
(questionado, perguntado e interrogado). Nesse "movimento", o interrogado (ser-aí) é compreendido desde sempre em uma direção prévia, denominada facticidade. $\mathrm{O}$ conceito de hermenêutica, portanto, "pretende indicar o modo unitário de abordar, concentrar, acessar a ela, isto é, de questionar e explicar a facticidade" (HEIDEGGER, 2012a, p. 15) a qual é compreendida como

[...] a designação para o caráter ontológico de "nosso" ser-aí "próprio". Mais especificamente, a expressão significa: esse ser-aí em cada ocasião (fenômeno da "ocasionalidade"; cf. demorar-se, não ter pressa, ser-aí-junto-a, ser-aí), na medida em que é "aí" em seu caráter ontológico no tocante ao seu ser (HEIDEGGER, 2012a, p. 13).

A hermenêutica da facticidade está relacionada ao poder-ser do ser-aí, revelando-se por meio de um caráter ontológico enquanto delimitação de suas principais estruturas no mundo. Compreendemos, assim, que o ser-aí existe na facticidade e o seu caráter hermenêutico diz respeito ao próprio questionamento e interpretação que o ser-aí faz de si mesmo enquanto um ente que existe.

Por meio da desconstrução da história da ontologia e da hermenêutica da facticidade, a ontologia de Heidegger é fundamental, pois está na base (é o que fundamenta) de todo pensamento filosófico. A ontologia fundamental busca resgatar o questionamento mais primordial e originário em que compreendemos o ser-aí de modo completamente distinto da metafísica tradicional. Para entender melhor o modo como a ontologia fundamental compreende o ser do ser-aí, Heidegger apresenta o seu terceiro subprojeto, intitulado de: analítica existencial, ou analítica do ser-aí.

\section{A analítica existencial enquanto subprojeto}

A analítica existencial é um tema central na filosofia de Heidegger, pois é ela a responsável pela análise do ente que nós mesmos somos, o ente que compreende ser e, por isso mesmo, pode questioná-lo no seio de uma ontologia fundamental (como uma condição necessária para a recolocação da pergunta fundamental). Heidegger explica, em Seminários de Zollikon, que Kant usou o termo "analítica” em sua Crítica da Razão Pura e que, a partir daí, ele retirou o termo para integrar a sua analítica existencial. Apesar de reconhecer que a palavra lhe serviria, sua interpretação se dá em um domínio diferenciado e não mais dos moldes kantianos. Por isso, temos que compreender que a interpretação de Heidegger é diferente, uma vez que ele não pretende continuar a posição de Kant ao se referir à analítica. Para Heidegger, a analítica tem a função de

[...] evidenciar a unidade original da função da capacidade de compreensão [...] a tarefa de mostrar o todo de uma unidade de condições ontológicas. A analítica como analítica ontológica não é um decompor em elementos, mas a articulação da unidade de uma 
estrutura. Esse é o fator essencial no meu conceito "analítica do Dasein" (HEIDEGGER, 2009b, p. 154).

A analítica existencial, portanto, não é compreendida enquanto análise que decompõe o objeto e o estuda (analisa) em partes. Primeiramente, porque o ser-aí não é objeto, sujeito, alma ou qualquer outra coisa que carregue consigo os pressupostos teóricos, subjetivistas ou empíricos. $\mathrm{O}$ ser-aí também não é propriamente o "Homem", pois ele não carrega consigo as definições tradicionais de animal racional, corpo, alma, razão, etc. O ser-aí, ao contrário, tem seu traço fundamental na relação com seu próprio ser, em que não há espaço para definições que se deem fora do âmbito existencial.

Ser-aí não é uma mudança linguística, um novo termo para se referir ao homem, à consciência ou ao sujeito. Do mesmo modo, ser-aí não é um mero termo criado para substituir algo, mas um modo de ser do ente que somos, que não havia sido pensado, tampouco questionado em meio às discussões filosóficas. Heidegger também não criou o termo Dasein, especificamente, para falar do fenômeno humano e sua existência, pois Kant e Hegel já haviam utilizado o termo Dasein, no entanto, estes não se referem ao nosso próprio existir quando falam de ser-aí.

Diante disso, Heidegger rompe, de todos os modos, com a ideia de que o ser-aí é algo determinado e de que pode ser analisado e explicado a partir de uma parte/região, como sua racionalidade, consciência ou espírito. A analítica é uma "análise fenomenológica do Dasein - e não do homem, tal como este é geralmente considerado, como sujeito de conhecimento e, ao mesmo tempo, objeto de disciplinas científicas" (GIACOIA JR, 2013, p. 65). Na analítica existencial o ser-aí é compreendido a partir da sua existência enquanto poder-ser e, assim:

As características que se podem extrair deste ente não são, portanto, "propriedades" simplesmente dadas de um ente simplesmente dado que possui esta ou aquela "configuração". As características constitutivas do ser-aí são sempre modos possíveis de ser e somente isso. Toda modalidade de ser deste ente é primordialmente ser. Por isso, o termo "ser-aî", reservado para designá-lo, não exprime a sua quididade como mesa, casa, árvore, mas sim o ser (HEIDEGGER, 2008b, p. 77-78).

Diante desta passagem, entendemos que o ser-aí não deve ser considerado um ente simplesmente dado, uma coisa em meio a outras, tampouco ser compreendido como se tivesse uma essência, enquanto comumente compreendida por substância. No entanto, se for possível falar em "essência” do ser-aí, esta pode ser, única e exclusivamente, a sua existência enquanto poder vir a ser. Este traço característico e "essencial” é, pois, a sua única determinação ontológica. 


\section{Referências}

DASTUR, F; CABESTAN, P. Daseinsanálise: fenomenologia e psicanálise. Trad. Alexander de Carvalho. Rio de Janeiro: Via Verita, 2015.

DUBOIS, C. Heidegger: introdução a uma leitura. Trad. Bernardo Barros Coelho de Oliveira. Rio de Janeiro: Jorge Zahar, 2004.

FIGAL, G. Fenomenologia da liberdade. Trad. Marco Antonio Casanova. Rio de Janeiro: Forense Universitária, 2005.

. Introdução a Martin Heidegger. Trad. Marco Antonio Casanova. Rio de Janeiro: Via Verita, 2016.

GADAMER, H-G. Hermenêutica e diferença ontológica. In: Hermenêutica em retrospectiva. Trad. Marco Antonio Casanova. Petrópolis, RJ: Vozes, 2012, p. 68-81.

GIACOIA JUNIOR, O. Heidegger urgente: introdução a um novo pensar. São Paulo: Três Estrelas, 2013.

HAAR, M. Heidegger e a essência do homem. Trad. Ana Cristina Alves. Lisboa: Instituto Piaget, 1990.

HEIDEGGER, M. Meu caminho para a fenomenologia. In: Sobre a questão do pensamento. Trad. Ernildo Stein. Petrópolis, RJ: Vozes, 2009a. p. 85-93.

. Ontologia - Hermenêutica da facticidade. Trad. Renato Kirchner.

Petrópolis, RJ: Vozes, 2012a. Vozes, 2009b.

Seminários de Zollikon. Trad. G. Arnhold; M. F. A. Prado. Petrópolis, RJ:

. Ser e tempo. Trad. Fausto Castilho. Campinas, SP: EdUNICAMP;

Petrópolis, RJ: Vozes, 2012b.

Ser e Tempo. Trad. Márcia Sá Cavalcanti Schuback - Petrópolis, RJ: Vozes, 2008b.

KAHLMEYER-MERTENS, R. S. 10 Lições sobre Heidegger. Petrópolis, RJ: Vozes, 2015.

MACDOWELL, J. A. A. A. A gênese da ontologia fundamental de Martin Heidegger: ensaio de caracterização do modo de pensar de Sein und Zeit. São Paulo: Loyola, 1993.

NUNES, B. Passagem para o poético: filosofia e poesia em Heidegger. São Paulo: Loyola, 2012.

Submissão: 13.05.2017 / Aceite: 30.05.2017 